Article

\title{
Colony Development and Reproductive Success of Bumblebees in an Urban Gradient
}

\author{
Chatura Vaidya ${ }^{1, *}$, Kaleigh Fisher ${ }^{2}$ and John Vandermeer ${ }^{1}$ \\ 1 Ecology and Evolutionary Biology, University of Michigan, 830 N University St, Ann Arbor, MI 48109, USA; \\ chatura@umich.edu or jvander@umich.edu \\ 2 Entomology, University of California, 900 University Ave, Riverside, CA 92521, USA; \\ kaleigh.fisher@email.ucr.edu \\ * Correspondence: chatura@umich.edu
}

Received: 17 April 2018; Accepted: 7 June 2018; Published: 9 June 2018

check for updates

\begin{abstract}
Approximately 35\% of all crop production is dependent on animal-mediated pollination. Many wild bee species are declining rapidly across North America and Europe, a potential consequence of land-use change driven by agricultural intensification and urbanization. In this study we assessed the impact of urbanization on the reproductive success and population growth rate of bumblebees in an urbanization gradient. We placed experimental nests in ten sites; all except one were community gardens, ranging from a 0-99\% degree of urbanization. Reproductive success and colony size were positively correlated with cumulative weight gain of the nests $(p<0.05)$. We did not find an effect of urbanization on the population growth rate of the nests or on forager activity $(p>0.05)$. Growth rate was strongly negatively affected by the abundance of wax moth larvae $(p<0.05)$ and positively correlated with parasite diversity $(p<0.05)$ and the number of foragers entering the nest $(p<0.01)$. With this study we show that not only bottom-up but also top-down effects are equally important for pollinator population dynamics.
\end{abstract}

Keywords: urban ecology; bumblebees; pollination; urbanization; parasitism; wax moth

\section{Introduction}

Pollination services are critical for many wild and crop plants and approximately 35\% of all crop production is dependent on animal-mediated pollination [1]. Although many farmers depend on honeybees (Apis mellifera) for crop pollination, bumblebees and other wild bees are responsible for a multitude of pollination services. In fact, recent research suggests positive associations of wild bees with fruit set regardless of honeybee abundance. A meta-analysis looking at studies conducted on 41 crop systems showed that an increase in wild bee visitation increased fruit set twice as much as with an increase in honeybee visitation [2]. Wild bee visitation in orchards synergistically increased honeybee pollination effectiveness due to interspecific interactions [3]; the presence of wild bees resulted in a higher proportion of between-row movements by honeybees resulting in higher fruit set. Reports of widespread decline in wild bee populations across North America and Europe over the past decades [4] are therefore understandably concerning. Causes of this decline are thought to be due to pesticide use, parasites, disease and habitat destruction [5] driven by increased land use due to agricultural intensification and urbanization [6].

About half of the world's population presently lives in urban areas [7]. Moreover, urbanization is projected to increase globally by 285\% between 2000 and 2030 [8]. Urbanization has resulted in major modifications to the landscape through the rise of concrete surfaces like roads, buildings and pavement accompanied by a loss in natural habitats or green spaces [9-11]. Thus urbanization can potentially affect population dynamics of bees by influencing direct factors vital for pollinator survival, such as a 
decline in nesting substrates and floral resources. However, green spaces in cities like urban parks and botanical gardens have been shown to harbor diverse wild bee populations [4,12]. More recently, the burgeoning urban agriculture movement across the United States shows promise to provide habitat for diverse insect species including pollinators [13-15] and has great potential to support ecosystem services like pollination, pest control and climate resilience [16]. There has been a recent interest in studying these relationships to test whether green spaces within cities will indeed support diverse native bee populations.

There seems to be no clear trend across different urban habitats with regards to pollinator abundance and diversity. A number of studies have tried to investigate factors that drive the composition of native pollinators within urban ecosystems with varying results. While some studies have found negative impacts of urbanization on both diversity and abundance $[4,14,17,18]$, while some have showed potential positive effects of urbanization when compared with agricultural areas $[19,20]$ and some have found unchanged bee assemblages in urban areas [21,22]. Yet others have found no significant patterns in abundance and diversity in urban landscapes $[23,24]$. In addition to the binary of urban versus rural, the degree of land-use change may also have strong consequences [20]. For example, in some sites having $<5 \%$ of natural habitat remaining, bee abundance and richness shows a steep decline whereas in sites with $>5 \%$ natural habitat, there is more than one outcome [25]. Different species show differential responses to the same anthropogenic drivers because they have a variety of life history traits and behaviors such as dietary needs, nesting site locations, body size, sociality and habitat specialization. For example, cavity-nesting bees and floral generalists seem to do better than ground-nesting bees and specialist bees (or floral specialists) in urban areas [24]. Several studies have shown that social bees tend to do worse than solitary bees with land-use change possibly due to exposure to pesticides $[25,26]$. There are also studies that have shown the opposite effect with solitary bees doing more poorly than social bees in urban areas [27].

The majority of the research conducted in this area uses abundance and diversity as the metrics for habitat suitability, which is a static approach. These metrics alone may not be representative of the quality and suitability of the habitat for pollinators [28,29]. Particularly in social bees, worker turnover is fast and hence may not be indicative of the success of the bees in those habitats. Point estimates of abundance can be misleading, as abundance of workers tends to change relatively quickly. Demographic variables such as reproductive success or population growth rate can give more relevant insight into long-term trends in population dynamics. So far only a few studies have reported reproductive success as a function of land use, in large part due to the difficulty of measuring reproductive success of wild bees. One study showed that suburban gardens support larger populations of Bombus terrestris by provisioning more abundant and floral resources than conventional farms [30]. Similarly, another study showed that spatiotemporal variation in floral resources in the landscape impact total abundance of bumblebees [31]. These results have important implications for the success of bumblebee colonies but both studies only focused on agricultural farms and suburban gardens, and consequently have limited applicability to the questions of how pollinators will fare in urban habitats. Social bees have colonies that live for months longer than solitary bees and can produce many (from tens to hundreds) foragers (i.e., workers) over the course of colony development. Availability of floral resources throughout the length of colony development (spring through fall) is important because production of offspring is largely dependent on the pollen and nectar resources stored within the nests. Secondly, there are factors other than resource availability, such as predation and/or parasitism that can also affect colony growth and reproductive success [32,33]. Along with bottom-up effects of resource availability, top-down effects on pollinators is a key research area that has not been fully explored in regards to their role in affecting population dynamics. Bees have various natural enemies, which include insects, protozoans and arachnids [34] and have been known to pose a serious threat to bees during all stages of their life cycles, from the brood to adult stage, as well as attacking the stored provisions in their nests [35-38]. Population dynamics of wild bees 
therefore can be driven from the bottom-up (i.e., by resource availability) or from top-down (i.e., by natural enemies), with urbanization seemingly having an indirect effect on both of them.

In this study, our aim was to understand how different landscapes affect the population dynamics of bumblebees. Bumblebees are social bees with long-lived colonies that persist from spring to fall in temperate regions. The success of a colony can be measured in the number of reproductives (i.e., queen and male bees) produced at the end of the season. The number of reproductives produced is, in turn, dependent on the growth of the colony i.e., the number of workers produced throughout the season. The growth rate of the colony will then depend on the availability of consistent and high-quality floral resources in the surrounding landscape as well as the challenges the colony might face due to threats posed by their natural enemies. The effect of urbanization and the possible refugia in urban community gardens (urban agriculture) on colony success is, thus, key to understanding the long-term prospects of these essential pollinators. To this effect, we set out to answer a specific question: How does urbanity, measured in terms of amount of concrete or impervious surface in the surrounding landscape, affect the population growth rate and reproductive success of bumblebee colonies via bottom-up or top-down effects? We predicted that as the amount of impervious surface in the landscape increases, the growth rate of the colonies and hence their reproductive success will decrease because it will be inhospitable to forage for floral resources in urban landscapes suggesting that bottom-up effects may play a larger role than top-down effects in driving the population dynamics. Alternately, we predicted that urbanization will have no effect on the population growth rate of bumblebee colonies if the amount of floral resources provided by urban community gardens are sufficient. In that case, it is possible that population dynamics will be driven more by top-down effects.

\section{Materials and Methods}

\subsection{Study Organism}

For this study we used bumblebees, namely Bombus impatiens as our study organisms. Bombus impatiens, the eastern bumblebee, is an abundant native to the Eastern United States and is readily available commercially and hence was selected for its ease of use.

\subsection{Site Selection}

An a priori gradient was used to select sites for this study and all plots chosen fell in an urbanization gradient scheme with 0 to 0.99 intensity of impervious surface. Apart from the natural site ( $0 \%$ impervious surface), all the nests were placed in urban community gardens which fell within this gradient. Land cover was analyzed using data from the National Land Cover Database (NLCD) with ArcGIS (Esri, Redlands, CA, USA). To assess the degree of urbanization, the intensity of impervious surface was calculated by including the proportion of medium and high-density development within $500 \mathrm{~m}, 1000 \mathrm{~m}, 1500 \mathrm{~m}$ and $2000 \mathrm{~m}$ of the surrounding landscape. Preliminary analysis showed that (Supplementary Information-Figures S1-S2) there was not much difference between the four scales mentioned above. Additionally, Mattesson \& Langellotto et al., 2009 conducted mark-recapture experiments with B. impatiens in urban gardens in NYC, USA and found that even though some of the gardens were within $500 \mathrm{~m}$ (within foraging range of bumblebees) of each other, they did not find the bees moving between these gardens. We therefore used the $500 \mathrm{~m}$ scale in all the analyses for degree of urbanization (Table 1). 
Table 1. Site characteristics with reference to where they fall in the urbanization gradient.

\begin{tabular}{|c|c|c|c|c|c|}
\hline Site Name & Site Code & Land Cover Type & \% Impervious Surface & Coordinates & Location \\
\hline E.S. George Reserve & ESGR & Natural & 0 & $\begin{array}{l}\text { N } 42.4590988 \\
\text { W 84.0137024 }\end{array}$ & Pinckney \\
\hline Campus Farm & $\mathrm{CF}$ & Rural & 4 & $\begin{array}{l}\text { N } 42.2989998 \\
\text { W } 83.6648026\end{array}$ & Ann Arbor \\
\hline Leslie Science Center & LSC & Suburban & 13 & $\begin{array}{l}\text { N } 42.3009987 \\
\text { W } 83.7292023\end{array}$ & Ann Arbor \\
\hline Green View Garden & GV & Suburban & 17 & $\begin{array}{l}\text { N } 42.2582016 \\
\text { W } 83.7630005\end{array}$ & Ann Arbor \\
\hline Ellsworth Garden & E & Suburban & 35 & $\begin{array}{l}\text { N } 42.2282982 \\
\text { W } 83.7169037\end{array}$ & Ann Arbor \\
\hline West Park & WP & Suburban & 38 & $\begin{array}{l}\text { N } 42.283699 \\
\text { W } 83.754303\end{array}$ & Ann Arbor \\
\hline Frog Island & FI & Suburban & 55 & $\begin{array}{l}\text { N } 42.2484016 \\
\text { W } 83.6122971 \\
\end{array}$ & Ypsilanti \\
\hline North Cass Garden & NC & Urban & 93 & $\begin{array}{l}\text { N } 42.3493996 \\
\text { W } 83.0660019 \\
\end{array}$ & Detroit \\
\hline Art Center Garden & ACG & Urban & 95 & $\begin{array}{l}\text { N } 42.3627904 \\
\text { W } 83.0650809\end{array}$ & Detroit \\
\hline Lafayette Greens & LG & Urban & 99 & $\begin{array}{l}\text { N } 42.3314018 \\
\text { W 83.0493011 }\end{array}$ & Downtown Detroit \\
\hline
\end{tabular}

\subsection{Experimental Setup}

Twelve nests of Bombus impatiens were purchased from Koppert, USA. Bombus impatiens, the eastern bumblebee, is abundant in northeastern USA and their nests are available commercially. The nests were small in size, even aged and came in with a founding queen and approximately 20-30 workers. The bees were housed in a ventilated inner plastic box with an observation lid, contained within a cardboard box. The inner plastic box, as well as the cardboard box had adjustable flight holes. Bees could fly in and out when both holes were left open, but could only fly into the box if only one hole was left open. Both flight holes were left open for the length of the experiment. The nest box came with an inbuilt sugar water box, which was removed prior to the placement of the nests. Nests were placed in 12 sites (one nest per site) in a random fashion with increasing degrees of urbanization; from 0-99\% urbanized area around the sites.

To protect the nest box from the elements, a corrugated plastic sheet was placed over the hive. The sheet was white in color so as to avoid excessive heating up of the nest box. The nest box itself was raised above the ground by placing it on a cinder block to avoid flooding. Additionally, two more bricks were kept on the top of the plastic sheet to secure the nest box from windy conditions. The nest box was protected from ants by applying tanglefoot to the bricks as well as to the base of the box. All nest boxes were placed under a bush or the shade of a tree to keep them out of direct sunlight. Prior to opening the nest entrance, all the nests were weighed and then weights were taken every week subsequently. Each week, the number of foragers entering and leaving the nest was noted for a period of $10 \mathrm{~min}$ (forager activity). Whenever possible, the number of foragers entering with pollen was also recorded. 2 nests were vandalized in the 3rd and 4th week of the study respectively. After 8 weeks, the first reproductives (males and/or new queens) were observed in the nest and the study was terminated to minimize commercially bred bees from escaping into the wild. To capture all the foragers, only one flight hole was left open for $24 \mathrm{~h}$. The nest entrance was then entirely closed and the box sealed in a plastic bag. The nest location was then observed for a period of $2 \mathrm{~h}$ to catch any returning foragers that were unable to enter the nest box the previous day. After $2 \mathrm{~h}$, if no foragers were seen for a period of more than 10-20 $\mathrm{min}$, it was assumed that no foragers were left behind. The boxes were all placed in a $-30^{\circ} \mathrm{C}$ freezer to kill the nest. 


\subsection{Nest Variables}

Each nest was dissected and the total number of each of the following were recorded-workers, males, gynes, new queen pupae, male pupae, worker pupae, number of hatched cells, larvae, eggs, parasitized larvae and parasitized pupae. If the nest was found to have produced males during brood count then it was assumed that all the pupae in the nest would eventually become males. Those pupae were counted in the reproductive success count. If a nest did not produce any reproductives, the pupae were then assumed to be worker pupae. Reproductive success (RS) was counted using the formula: $R S=M+3 Q$; where $M=$ males and $Q=$ new queens. Per capita investment in queens was considered to be three times as much as that in males [38]. Following brood count, all the parasites and predators found in the nest were counted and identified to species wherever possible.

\subsection{Data Analysis}

All analyses were carried out in R v.3.1.1 [39]. To test the drivers of colony development, we modeled the longitudinal growth of nest weights with time using linear mixed effects models (with identity link function). We used site as a random effect to account for the intra-site correlation. We assumed that nest weights changed linearly with time. Time was measured in weeks, with the first measurement coded as week 0 . To assess whether a given variable affected the rate of change of growth, we tested the interaction term of that variable with time. The fixed effects for this model included predictors that did not vary with time (i.e., the initial number of workers, urbanization gradient, abundance of wax moth larvae (a major nest parasite) and Shannon's index of parasite diversity at the end of the study) and a time-varying predictor (i.e., weekly measurement of the number of foragers entering the nest in a $10 \mathrm{~min}$ period). All the variables were scaled to have a zero mean and standard deviation of 1 . To address the large differences in weight between sites we added a random slope to the linear mixed effect model. These models were fit using the lme() function from the nlme package [40].

Associations between nest variables (RS, number of larvae and surviving workers) and predictors like cumulative weight gain, parasite diversity and urbanization gradient were assessed using generalized linear models (GLM) with quasi-Poisson links to account for overdispersion. For all these nest variables, however, urbanization gradient and parasite diversity were strongly correlated (variance inflation factor $>5$ ). Thus, urbanization gradient and parasite diversity were assessed using separate models along with the other predictors to prevent variance inflation..

To elucidate the drivers of foraging activity for the proportion of foragers entering the nest with pollen only, we fit a binomial generalized linear mixed model (GLMM) (with logistic link function) with the proportion of foragers entering with pollen as the response variable, cumulative weight gain, number of wax moth larvae and intensity of urbanization as fixed effects and site as a random effect.

\section{Results}

\subsection{Nest Weights}

At the beginning of the study the weights of the nest were $633.4 \pm 13.8 \mathrm{~g}$ (mean \pm SD). This included all the bees as well as the weight of the internal plastic nest box in which the colonies were housed. Barring three nests, all nests gained weight over the course of the experiment by $52.5 \pm 62.3 \mathrm{~g}$ (mean $\pm \mathrm{SD}$ ). The seven nests that gained weight grew by $83.3 \pm 46.2 \mathrm{~g}$ (mean $\pm \mathrm{SD}$ ) and the 3 nests that never grew over the course of the experiment showed a decline in weight by $-19.3 \pm 4.7 \mathrm{~g}($ mean $\pm \mathrm{SD})$ (Figure 1; Supplementary information-Table S1). 


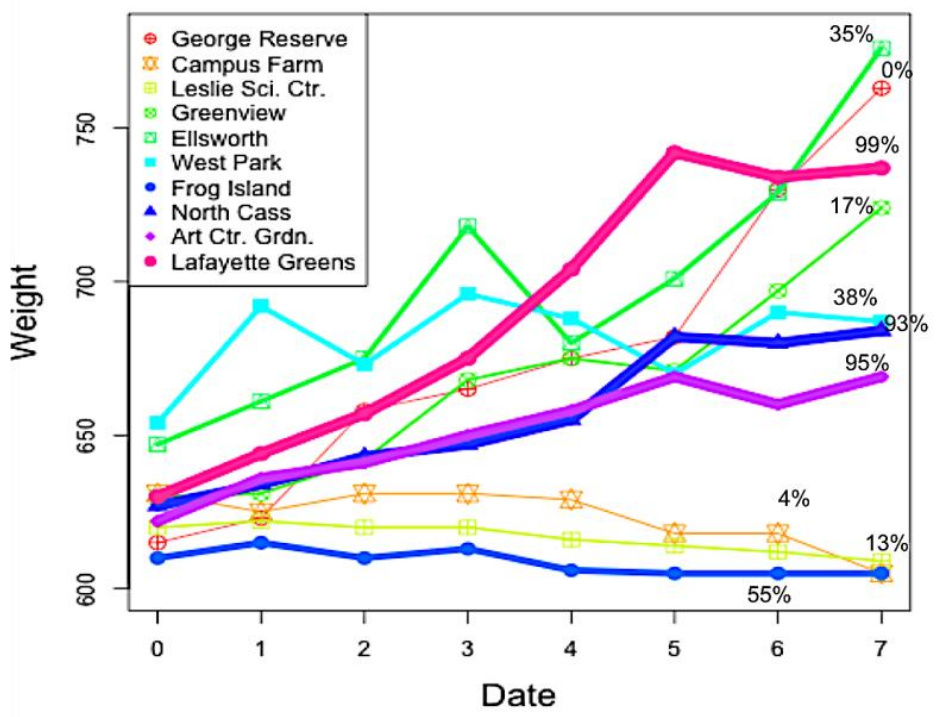

Figure 1. Change in weight of bumblebee nests over the entire length of the study. Colored lines represent the different sites in which the nests were placed during the study and numbers with percentage at the end of each line denote the percent impervious surface in the surrounding landscape of each site.

\subsection{Nest Variables}

\subsubsection{Reproductive Success}

At the time of collection, all colonies produced a variable number of reproductives, with some only producing males and some producing both males and new queens (gynes), with the exception of one colony that had not yet produced reproductives (neither males nor gynes). The maximum number of gynes produced in any one nest was eight and the maximum number of males was 69 (in total, 15 new queens and 110 males, not including the male pupae) (Supplementary information-Table S1). Only two out of the ten nests produced gynes and all except one nest produced males. Results from both the GLM models (with Shannon's index of parasite diversity and degree of urbanization each) showed a positive association with the cumulative weight gain of the nests with the reproductive success of the nest $(p=0.01)$ (Table 2).

Table 2. Results from generalized linear models for all the nest variables.

\begin{tabular}{cccccc}
\hline Response & Predictor & Coeff & SE & T & $p$ \\
\hline Reproductive success & Cumulative weight gain & 0.019 & 0.005 & 3.48 & $0.01^{*}$ \\
Model 1 & Urbanization gradient & 1.05 & 0.59 & 1.79 & 0.112 \\
\hline \multirow{2}{*}{ Model 2 } & Cumulative weight gain & 0.022 & 0.006 & 3.73 & $0.007^{* *}$ \\
& Parasite diversity & -1.1 & 0.55 & -1.98 & 0.09 \\
\hline Surviving workers & Cumulative weight gain & 0.01 & 0.003 & 2.44 & $0.0447^{*}$ \\
Model 1 & Urbanization gradient & 0.32 & 0.48 & 0.67 & 0.53 \\
\hline \multirow{2}{*}{ Model 2 } & Cumulative weight gain & 0.01 & 0.004 & 1.94 & 0.09 \\
& Parasite diversity & -0.01 & 0.54 & -0.01 & 0.99 \\
\hline Larvae & Cumulative weight gain & 0.018 & 0.004 & 3.95 & $0.005^{* *}$ \\
Model 1 & Urbanization gradient & 0.84 & 0.52 & 1.63 & 0.15 \\
\hline \multirow{2}{*}{ Model 2 } & Cumulative weight gain & 0.02 & 0.005 & 3.8 & $0.0067^{* *}$ \\
& Parasite diversity & -0.68 & 0.52 & -1.31 & 0.23 \\
\hline
\end{tabular}

Italicized variables were found significant. ${ }^{*} p<0.05,{ }^{* *} p<0.01$. 


\subsubsection{Brood}

The maximum number of viable pupae that were produced in any one nest was 92 and the minimum was $0(34.8 \pm 29.84$, mean \pm SD). All but one nest had viable larvae, with the maximum in any one nest being 336 and a minimum of 0 (108.7 \pm 123.67 , mean \pm SD). The number of pupae produced was positively associated with the number of larvae in the nest $(p<0.01)$. Results from the 2 GLM models (cumulative weight gain with Shannon's index of parasite diversity and degree of urbanization each as predictors) showed a positive association with the cumulative weight gain of the nests with the number of viable larvae ( $p=0.0067$ and $p=0.005$ respectively) and the number of surviving workers in the nest ( $p=0.09$ and $p=0.04$ respectively) (Table 2). The maximum number of surviving workers found was $166(78.1 \pm 52.01$, mean $\pm \mathrm{SD})$.

\subsubsection{Natural Enemies}

We observed three nest parasites and two predators during the course of this study. Parasites observed were wax moth larvae (Vitula edmandsae), endoparasitic larvae (Brachicoma devia) and phorid fly larvae and pupae (Apocephalus borealis). The two predators found in the nest were: a grass spider commonly found in Michigan, Agelenopsis spp. and earwigs (Forficula auricularia). All the parasites/predators found in the nest were either brood parasites or prey on the adult bees. We calculated the Shannon's index for parasite diversity and it was negatively correlated with increasing urbanization, albeit not statistically significant (Pearson's product moment correlation, $r=-0.58, t=-1.99, d f=8, p$-value $=0.08)$.

\subsubsection{Forager Activity}

Cumulative weight gain was positively associated with the proportion of foragers carrying pollen into the nest $(p<0.005)$, while intensity of urbanization showed poor evidence of association (negative effect, $p=0.09$ ). Wax moth larvae showed no evidence of association on forager activity (Table 3).

Table 3. Results from generalized linear models for proportion of pollen foragers.

\begin{tabular}{cccccc}
\hline Response & Predictor & Coeff & SE & T & $p$ \\
\hline \multirow{3}{*}{ Proportion of pollen foragers } & Cumulative weight gain & 0.0076 & 0.0027 & 2.838 & $0.00453^{* *}$ \\
& Urbanization gradient & -0.476 & 0.2 .80 & -1.701 & 0.09 \\
& Abundance of wax moth larvae & $9.34 \times 10-5$ & 0.002 & 0.047 & 0.96 \\
\hline
\end{tabular}

Italicized variables were found significant. ${ }^{* *} p<0.01$.

\subsubsection{Colony Development (Rate of Weight Change)}

Results from the linear mixed effect models revealed that the rate of change in weight per week was not influenced by the urbanization gradient (Figure 2), but was positively associated with the Shannon's index of parasite diversity $(p<0.05)$ and the number of foragers entering per ten minutes $(p<0.01)$ and negatively associated with the abundance of wax moth larvae $(p<0.05)$ in the nests (Figure 3, Table 4). We included the total number of workers that came with the nests $(20.7 \pm 7.11$, mean \pm SD) as a covariate in the analysis for colony development to account for the effect it would have on colony development but found that it had no effect on the rate of change of weight per week in the model. 


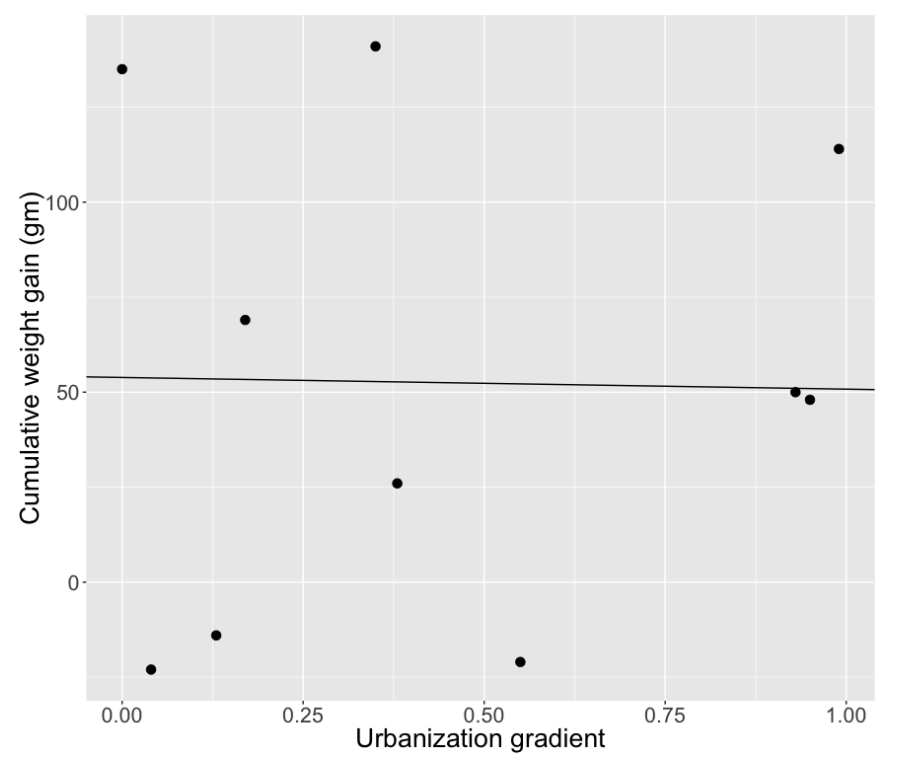

Figure 2. Plot of cumulative weight gain vs. degree of urbanization. Black trendline shows the mean cumulative weight gain as a function of degree of urbanization as estimated model 1 in Table 4 .

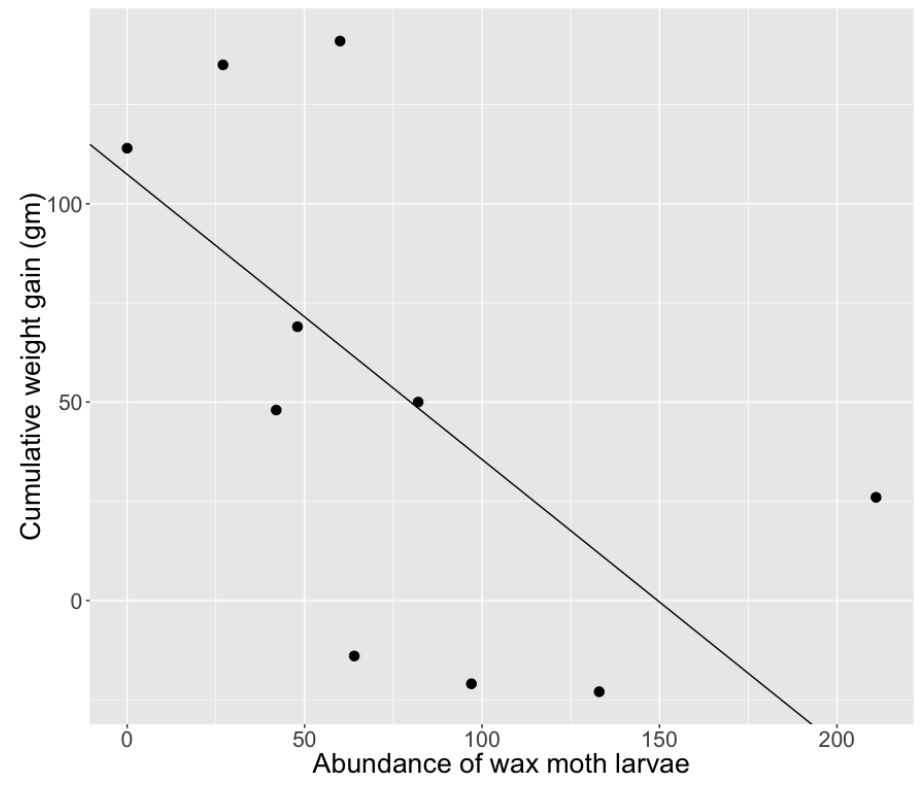

Figure 3. Plot of cumulative weight gain vs. abundance of wax moth larvae. Black trendline shows the mean cumulative weight gain as a function of abundance of wax moth larvae as estimated in model 1 in Table 4.

Table 4. Results from generalized linear mixed-effect models for colony development.

\begin{tabular}{cccccc}
\hline Response & Predictor & Coeff & SE & T & $p$ \\
\hline Rate of weight change over time & Urbanization gradient & 3.133 & 1.87 & 1.68 & 0.098 \\
& Intial number of workers & 0.89 & 1.43 & 0.63 & 0.533 \\
Interaction term is date with all & Abundance of wax moth larvae & -3.74 & 1.53 & -2.45 & $* 0.0169$ \\
predictors & Foragers entering nest per 10 min per week & 2.15 & 0.71 & 3.02 & $* * 0.0036$ \\
& Parasite Diversity & 4.75 & 1.87 & 2.55 & $* 0.0134$ \\
\hline
\end{tabular}

Italicized variables were found significant. ${ }^{*} p<0.05,{ }^{* *} p<0.01$ 


\section{Discussion}

Contrary to our expectations, we found no effect of degree of urbanization on the colony development and reproductive success of bumblebees. All the nests in this study were placed in urban community gardens, which are usually rich in floral resources, particularly in summer and fall (pers. observation). It is therefore plausible that the effect of urbanization was dampened because the gardens in which the nests were placed were probably sufficient in providing floral resources to these bumblebee colonies regardless of the degree of urbanization in the surrounding landscape.

Although we did not measure floral diversity in these gardens, we did measure forager activity throughout the study and found that it had a positive association with rate in change of weight per week as well as the cumulative weight gain of the nests. We considered forager activity as a proxy for (analogous to) floral availability in the surrounding landscape, as the proportion of foragers returning with pollen was positively correlated to the total weight gain of the nests. The proportion of pollen foragers also did not seem to be affected by the degree of urbanization (negative effect was not found to be significant). In colonies that had a higher number of foragers collecting more resources (i.e., nectar and pollen), growth rate was faster, which is in line with studies that have found similar results [41]. If flowering resources were sparsely available and farther from the nest, which would be expected in urban areas, such that energy spent foraging outweighs energy gained (nectar and pollen) then returning foragers would make a net loss and you would expect the colony growth rate to decline. On the other hand, if the foragers make a net profit after a bout of foraging then you would expect the colony growth rate to keep increasing [42]. This would be possible only if the flowering resources were readily available in the surrounding landscape. In areas of higher percent impervious surface such as one site in Detroit with 99\% impervious surface $500 \mathrm{~m}$ around the nest, the garden area was probably the only place of forage for the bumblebees. Therefore, even if the urban landscape was inhospitable for foraging, the habitat patch, which in this case was the urban community gardens, may have provided the bees with all their pollen and nectar needs. Especially for sites in Detroit, Glaum et al. (2017) found that abundance and diversity of bumblebees was higher than sites with high percent impervious surface outside of Detroit [43], possibly due to an abundance of vacant lots within Detroit. Vacant lots can serve as good habitats for both floral and nesting resources for wild bees [44], therefore it is possible that along with community gardens, vacant lots too may have supplemented the availability of floral resources for sites in Detroit. However, it is possible that the lack of correlation of colony development and RS with degree of urbanization in our study could be due to something other than floral availability.

Colony growth and reproductive success can also be affected by factors other than resource availability, such as predation and parasitism. In our study we found a total of five nest parasites and predators. We observed two predators in the nest-Agelenopsis spp., which are grass spiders that prey on bumblebee workers and Forficula auricularia, European earwigs, that will prey on the old wax comb but also sometimes on bumblebee larvae and pupae in the nest (pers. observation). Two species of Diptera-phorid fly, Apocephalus borealis (it's larvae and pupae) and B. devia larvae were found in the nests. Brachicoma devia larvae feed on the larvae and pupae of bees [45] while phorid flies are parasitoid flies that oviposit their eggs in the host (bumblebee workers) after which the larvae feed on the thoracic flight muscle and pupate outside the host $[46,47]$. The third group of parasites found in the nest was the larvae of Vitula edmandsae, a wax moth. Wax moth larvae prey on the old comb of the colony, which usually consists of hatched brood cells. If the density of the wax moth larvae increases, they may attack the unhatched brood cells killing bumblebee larvae and/or pupae [30]. In our study, we found that the abundance of wax moth larvae negatively affected colony development. For colonies with a lower growth rate, it is possible that the rate of predation on the brood comb was greater than the rate of replenishing the comb with newly foraged pollen and nectar which could explain the decline in growth rate in heavily infested nests. We also found that the Shannon's index of parasite diversity was positively associated with colony development. Most of the parasites and predators in the nest seem to have host overlap, with wax moth larvae and earwigs preying on the 
old comb and possibly bumblebee larvae and pupae, spiders and phorid flies on bumblebee workers and B. devia and wax moth larvae on bumblebee larvae. It is therefore possible that competition for resources kept the population of the predators and parasites regulated. If there is no competition, i.e., when the parasite diversity is low, the parasites seem to grow unchecked and have a greater impact on host density. We also found that the Shannon's index of parasite diversity was negatively associated with the degree of urbanization, although not significantly. Hence it is possible that there was an indirect effect of urbanization such that there were top-down predator effects on the parasites in areas with low percent impervious surface, regulating their populations.

As mentioned above, reproductive success of the nests as well as the number of surviving workers were also significantly positively associated with the cumulative weight gain of the nests. These results are similar to a study that looked at effects of food supplementation on colony development in bumblebees in which food supplementation significantly increased colony size as well as reproductive success [38]. Bumblebee colonies require a consistent supply of pollen and nectar throughout the growing season (early spring- late summer) in order to reproduce. Therefore it is possible that a nest would produce reproductives only when there are enough pollen and nectar reserves to feed the brood including the new queen and male larvae and pupae. If a colony is unable to provision for the brood sufficiently, the founding queen will likely never reach a stage where any substantial investment in reproductives takes place. The number of gynes and males a colony produces determines the reproductive success of a colony. Males require much less investment than gynes do-gynes are usually larger, weighing more than males, their development time is longer than males and they typically spend more time after they emerge in the nest using up resources, until ready to leave. Therefore nests with larger colony sizes (i.e., number of surviving workers) and higher cumulative weight gain can be expected to invest more in new queens than males if there is sufficient floral resource availability in the surround. Recently, a few studies have shown that greater availability of floral resources will lead to an increased maternal investment in gynes [48] and that maternal investment is much more queen biased when floral resources are nearer to the nest during time of reproduction in a solitary leafcutter bee species [49]. This can imply that shortages in floral availability in the reproductive phase and possibly not the growth phase (when a queen is only producing workers) of the colony can impact reproductive success. In our study, the two nests that did produce new queens, produced males as well. It is possible that colony investment in new queens switched mid-season (late summer) either because floral resources suddenly became available or because foraging bouts became more successful due to a higher rate of collection of resources [41]. However, floral resource availability or lack thereof is just one of the possibilities for more male biased colonies. We did not find any correlation between the number of surviving workers or cumulative weight gain and a colony's preference for producing gynes over males. Our results are similar to another study, which also did not find any correlation between colony size and gyne production, but found that larger colonies were disproportionately male biased [50]. In our study, at the time of collection, only $20 \%$ of the nests produced both new queens and males and $80 \%$ produced only males. Our results are in agreement with several studies that have looked at bumblebee reproduction and sexual allocation being usually male biased in natural conditions [38]. Most studies that have looked at colony growth and reproductive success in bumblebees have found that there is an intrinsic variation in sexual allocation during the reproductive phase. Even with enough floral resources in the landscape to warrant a more queen biased outcome, colonies seem to produce males over queens [31]. This intrinsic variation of sexual allocation between colonies regardless of resource availability, has been reported by a number of studies and can possibly be attributed to workers laying eggs towards the end of the colony life cycle and skewing the outcome to a male biased colony [51,52].

We did not measure protozoan parasites like Crithida bombi and Nosema bombi in bumblebee workers, which are known to quickly spread through the colony and affect the performance of the workers and seem to increase in prevalence with urbanization in some bumblebee species such as Bombus terrestris [53]. However if colonies have a higher initial size before being transferred to the 
field, fitness of the colonies may not be affected by these parasites [35]. Even though we did not find any correlation with initial size of the colony and population growth rate, it is still possible that the 3 nests that never grew in our study, was a result of infection by these parasites. We did not observe any new eggs, larvae or pupae in one of these nests (out of the 3 above) after placing it in the field, which could also be due to low queen fecundity [54].

In addition to the above-mentioned factors, there are other exogenous factors that may affect the colony performance and reproductive success of bumblebees such as microclimatic conditions, for example, the amount of solar radiation on the nest boxes. Even though all the nest boxes were kept under a tree or a bush, each nest was not monitored to ensure that it was shaded throughout the length of the day. Regardless, B. impatiens have been known to be very resilient with temperature fluctuations so this likely had a minimal effect, if at all, on the nests in the study [55]. However, ambient temperature along with wind speed and humidity can all affect foraging performance of bumblebees [3]. We also did not dissect surviving workers in all the nests to look for parasitization by conopid fly larvae, known to severely affect lifespan of foragers, resulting in a decline in colony size and therefore growth rate [51,56]. Investigations into these factors can give further insight into successful foraging bouts and their correlation with the population growth rate of the colony. Additionally, we only had a total of ten sites in our study and perhaps a larger sample size may be necessary to see bigger differences. Future studies should consider increasing the sample size or consider establishing two sites with similar percent impervious surface along the urbanization gradient.

To minimize the escape of commercially bred reproductives, the study was terminated as soon as the first few reproductives were seen in the nests. Most of the nests that grew had developing larvae and pupae at the time of dissection. The final reproductive output of all these nests is therefore unknown. It is also possible that some males had left the nests before the study was terminated. If we had kept the nests in the field a little longer, we may have got a slightly different estimate of the reproductive success of the nests. Additionally, founding queens were only placed in the field after the first brood had emerged. Bees emerging in the spring rely on native plants and trees in bloom to replenish their fat reserves, used during hibernation and to provision for the first batch of worker bees [57]. Another limiting factor for founding queens in urban areas may be suitable nesting sites. Bumblebees usually nest in the ground and urban areas with high percent impervious surface like concrete roads, parking lots, etc., and can be impermeable for successful nest initiation. Therefore this study may not be completely representative of the true effects of urbanization on the reproductive success of bumblebees because it is during this initial phase of nest establishment that differences between habitats might be most pronounced. Nonetheless, this does not diminish the fact that resource availability is important throughout the growing season for a successful lifecycle. To the best of our knowledge, nobody has looked at the effects of urbanization on the population dynamics of bumblebees. Our study indicates that urbanization does not have to be synonymous with negative impact, especially on bumblebee populations, and it is likely a result of the habitat provided by green spaces like parks and community gardens in highly urbanized landscapes.

\section{Conclusions}

Our study did not find any evidence for the effect of urbanization on bumblebee survival and reproductive success. However, it did find that abundance of a major parasite had a significant negative impact on the growth rate of the bumblebee nests. Our study indicates that population dynamics of bees can be driven by a combination of resources (bottom-up) and natural enemies (top-down). With the decline in pollinators in recent decades, it is important to provide refuges for pollinators in areas of limited green spaces and urban agriculture seems to be a fitting source of pollen and nectar resource, while itself benefiting from these pollinators as they provide a key ecosystem service of pollinating their plants. Even though different species of bees depending on their sociality, nesting ecology, body size and foraging ecology can be differentially affected by the same drivers of 
urbanization [58-60], our study shows that urban community gardens have the potential to increase availability of resources and improve the quality of the habitat in an otherwise inhospitable landscape.

Supplementary Materials: The following are available online at http:/ /www.mdpi.com/2071-1050/10/6/1936/s1, Figure S1: Plots of \% impervious surface cover at different landscape scales with log of cumulative weight gain of the nests, Figure S2: Plot of \% impervious surface cover at $500 \mathrm{~m}$ scale vs all \% impervious surface cover at all other scales. Table S1: Site characteristics and nest variables with reference to where they fall in the urbanization gradient.

Author Contributions: C.V. conceived the study; C.V. and J.V. designed the study; C.V. and K.F. collected the data; C.V. analyzed the data; C.V. wrote the manuscript; J.V. and K.F. helped with editing the manuscript.

Funding: This study was funded by UM Rackham graduate student research grant and UM ecology \& Evolutionary Biology block grant.

Acknowledgments: We are grateful to all the gardeners and garden organizations in South East Michigan that allowed us to use their space for this study. We would like to thank Pranav Yajnik for help with statistical analysis and I. Perfecto, C. Badgeley, G. Fitch and J. Morris for helpful comments on earlier versions of the manuscript. We thank M.C. Simao for generously providing GIS profiles for the sites.

Conflicts of Interest: The authors declare no conflict of interest. The funding sponsors had no role in the design of the study; in the collection, analyses, or interpretation of data; in the writing of the manuscript, and in the decision to publish the results.

\section{References}

1. Klein, A.M.; Vaissiere, B.E.; Cane, J.H.; Steffan-Dewenter, I.; Cunningham, S.A.; Kremen, C.; Tscharntke, T. Importance of pollinators in changing landscapes for world crops. Proc. R. Soc. Lond. B 2007, 274, 303-313. [CrossRef] [PubMed]

2. Garibaldi, L.A.; Steffan-Dewenter, I.; Winfree, R.; Aizen, M.A.; Bommarco, R.; Cunningham, S.A.; Kremen, C.; Carvalheiro, L.G.; Afik, O.; Bartomeus, I.; et al. Wild pollinators enhance fruit set of crops regardless of honey bee abundance. Science 2013, 339, 1608-1611. [CrossRef] [PubMed]

3. Brittain, C.; Williams, N.; Kremen, C.; Klein, A.M. Synergistic effects of non-Apis bees and honey bees for pollination services. Proc. R. Soc. Lond. B Biol. Sci. 2013, 280, 20122767. [CrossRef] [PubMed]

4. Ahrne, K.; Bengtsson, J.; Elmqvist, T. Bumble Bees (Bombus spp.) along a Gradient of Increasing Urbanization. PLoS ONE 2009, 4, E5574. [CrossRef] [PubMed]

5. Goulson, D.; Nicholls, E.; Botías, C.; Rotheray, E.L. Bee declines driven by combined stress from parasites, pesticides, and lack of flowers. Science 2015, 347, 1255957. [CrossRef] [PubMed]

6. Koh, I.; Lonsdorf, E.V.; Williams, N.M.; Brittain, C.; Isaacs, R.; Gibbs, J.; Ricketts, T.H. Modeling the status, trends, and impacts of wild bee abundance in the United States. Proc. Natl. Acad. Sci. USA 2016, 113, 140-145. [CrossRef] [PubMed]

7. Grimm, N.B.; Faeth, S.H.; Golubiewski, N.E.; Redman, C.L.; Wu, J.G.; Bai, X.; Briggs, J.M. Global change and the ecology of cities. Science 2008, 319, 756-760. [CrossRef] [PubMed]

8. Seto, K.C.; Güneralp, B.; Hutyra, L.R. Global forecasts of urban expansion to 2030 and direct impacts on biodiversity and carbon pools. Proc. Natl. Acad. Sci. USA 2012, 109, 16083-16088. [CrossRef] [PubMed]

9. Geslin, B.; Gauzens, B.; Thebault, E.; Dajoz, I. Plant pollinator networks along a gradient of urbanisation. PLOS ONE 2013, 8, e63421. [CrossRef] [PubMed]

10. Martins, A.C.; Gonçalves, R.B.; Melo, G.A.R. Changes in wild bee fauna of a grassland in Brazil reveal negative effects associated with growing urbanization during the last 40 years. Zoologia (Curitiba) 2013, 30, 157-176. [CrossRef]

11. Williams, N.M.; Winfree, R. Local habitat charac-teristics but not landscape urbanization drive pollinator visitation and native plant pollination in forest remnants. Biol. Conserv. 2013, 160, 10-18. [CrossRef]

12. McFrederick, Q.S.; Le Buhn, G. Are urban parks refuges for bumble bees Bombus spp. (Hymenoptera: Apidae)? Biol. Conserv. 2006, 129, 372-382. [CrossRef]

13. Colding, J.; Lundberg, J.; Folke, C. Incorporating Green-area User Groups in Urban Ecosystem Management. AMBIO J. Hum. Environ. 2006, 35, 237-244. [CrossRef]

14. Matteson, K.C.; Ascher, J.S.; Langellotto, G.A. Bee richness and abundance in New York city urban gardens. Ann. Entomol. Soc. Am. 2008, 101, 140-150. [CrossRef] 
15. Matteson, K.C.; Langelotto, G. Determinates of inner city butterfly and bee species richness. Urban Ecosyst. 2010, 13, 333-347. [CrossRef]

16. Lin, B.B.; Philpott, S.M.; Jha, S. The future of urban agriculture and biodiversity-ecosystem services: Challenges and next steps. Basic Appl. Ecol. 2015, 16, 189-201. [CrossRef]

17. Tonietto, R.; Fant, J.; Ascher, J.; Ellis, K.; Larkin, D. A comparison of bee communities of Chicago green roofs, parks and prairies. Lands. Urban Plan. 2011, 103, 102-108. [CrossRef]

18. Kearns, C.A.; Oliveras, D.M. Environmental factors affecting bee diversity in urban and remote grassland plots in Boulder, Colorado. J. Insect Conserv. 2009, 13, 655-665. [CrossRef]

19. Baldock, K.C.; Goddard, M.A.; Hicks, D.M.; Kunin, W.E.; Mitschunas, N.; Osgathorpe, L.M.; Potts, S.G.; Robertson, K.M.; Scott, A.V.; Stone, G.N.; et al. Where is the UK's pollinator biodiversity? The importance of urban areas for flower-visiting insects. Proc. R. Soc. Lond. B 2015, 282. [CrossRef] [PubMed]

20. Theodorou, P.; Albig, K.; Radzevičiūtè, R.; Settele, J.; Schweiger, O.; Murray, T.E.; Paxton, R.J. The structure of flower visitor networks in relation to pollination across an agricultural to urban gradient. Funct. Ecol. 2017, 31, 838-847. [CrossRef]

21. Fetridge, E.D.; Ascher, J.S.; Langellotto, G.A. The Bee Fauna of Residential Gardens in a Suburb of New York City (Hymenoptera: Apoidea). Ann. Entomol. Soc. Am. 2008, 101, 1067-1077. [CrossRef]

22. Frankie, G.W.; Thorp, R.W.; Schindler, M.; Hernandez, J.; Ertter, B.; Rizzardi, M. Ecological patterns of bees and their host ornamental flowers in two northern California cities. J. Kansas Entomol. Soc. 2005, 78, 227-246. [CrossRef]

23. McIntyre, N.E.; Hostetler, M.E. Effects of urban land use on pollinator (Hymenoptera: Apoidea) communities in a desert metropolis. Basic Appl. Ecol. 2001, 2, 209-218.

24. Cane, J.H.; Minckley, R.L.; Kervin, L.; Roulston, T.H.; Williams, N. Complex responses within a desert bee guild (Hymenoptera: Apiformes) to urban habitat fragmentation. Ecol. Appl. 2006, 16, 632-644. [CrossRef]

25. Winfree, R.; Bartomeus, I.; Cariveau, D. Native pollinators in anthropogenic habitats. Ann. Rev. Ecol. Evol. Syst. 2011, 42, 1-22. [CrossRef]

26. Theodorou, P.; Radzevičiūtè, R.; Settele, J.; Schweiger, O.; Murray, T.E.; Paxton, R.J. Pollination services enhanced with urbanization despite increasing pollinator parasitism. Proc. R. Soc. Lond. B 2016, 283, 20160561. [CrossRef] [PubMed]

27. Banaszak-Cibicka, W.; Zmihorski, M. Wild bees along an urban gradient: Winners and losers. J. Insect Conserv. 2011, 16, 331-343.

28. Van Horne, B. Density as a misleading indicator of habitat quality. J. Wildl. Manag. 1983, 47, $893-901$. [CrossRef]

29. Henry, M.; Cosson, J.F.; Pons, J.M. Abundance may be a misleading indicator of fragmentation-sensitivity: The case of fig-eating bats. Biol. Conserv. 2007, 139, 462-467. [CrossRef]

30. Goulson, D.; Hughes, W.O.H.; Derwent, L.C.; Stout, J.C. Colony growth of the bumblebee, Bombus terrestris in improved and conventional agricultural and suburban habitats. Oecologia 2002, 130, 267-273. [CrossRef] [PubMed]

31. Williams, N.M.; Regetz, J.; Kremen, C. Landscape-scale resources promote colony growth but not reproductive performance of bumble bees. Ecology 2012, 93, 1049-1058. [CrossRef] [PubMed]

32. Goulson, D. Bumblebees: Behaviour, Ecology, and Conservation; Oxford University Press on Demand: New York, NY, USA, 2010.

33. Schmid-Hempel, P. Evolutionary Parasitology the Integrated Study of Infections, Immunology, Ecology, and Genetics; No. 574.5249 S2. 2011; Oxford Scholarship Online: Oxford, UK, 2013.

34. Roulston, T.A.H.; Goodell, K. The role of resources and risks in regulating wild bee populations. Ann. Rev. Entomol. 2011, 56, 293-312. [CrossRef] [PubMed]

35. Imhoof, B.; Schmid-Hempel, P. Colony success of the bumble bee, Bombus terrestris, in relation to infections by two protozoan parasites, Crithidia bombi and Nosema bombi. Insectes Sociaux 1999, 46, 233-238. [CrossRef]

36. Otterstatter, M.C.; Gegear, R.J.; Colla, S.R.; Thomson, J.D. Effects of parasitic mites and protozoa on the flower constancy and foraging rate of bumble bees. Behav. Ecol. Sociobiol. 2005, 58, 383-389. [CrossRef]

37. Otti, O.; Schmid-Hempel, P. A field experiment on the effect of Nosema bombi in colonies of the bumblebee Bombus terrestris. Ecol. Entomol. 2008, 33, 577-582. [CrossRef]

38. Pelletier, L.; McNeil, J.N. The effect of food supplementation on reproductive success in bumblebee field colonies. Oikos 2003, 103, 688-694. [CrossRef] 
39. R Core Team. R: A Language and Environment for Statistical Computing; R Foundation for Statistical Computing: Vienna, Austria, 2014.

40. Pinheiro, J.; Bates, D.; DebRoy, S.; Sarkar, D.; R Core Team. nlme: Linear and Nonlinear Mixed Effects Models; R Package Version 3.1-117; R Core Team: Vienna, Austria, 2014.

41. Schmid-Hempel, R.; Schmid-Hempel, P. Colony performance and immunocompetence of a social insect, Bombus terrestris, in poor and variable environments. Funct. Ecol. 1998, 12, 22-30. [CrossRef]

42. Cresswell, J.E.; Osborne, J.L.; Goulson, D. An economic model of the limits to foraging range in central place foragers with numerical solutions for bumblebees. Ecol. Entomol. 2000, 25, 249-255. [CrossRef]

43. Glaum, P.; Simao, M.C.; Vaidya, C.; Fitch, G.; Iulinao, B. Big city Bombus: Using natural history and land-use history to find significant environmental drivers in bumble-bee declines in urban development. R. Soc. Open Sci. 2017, 4, 170156. [CrossRef] [PubMed]

44. Gardiner, M.M.; Burkman, C.E.; Prajzner, S.P. The value of urban vacant land to support arthropod biodiversity and ecosystem services. Environ. Entomol. 2013, 42, 1123-1136. [CrossRef] [PubMed]

45. Alford, D.V. Bumblebees; Davis-Poynter: London, UK, 1975.

46. Cohen, H.; Quistberg, R.D.; Philpott, S.M. Vegetation Management and Host Density Influence Bee-Parasite Interactions in Urban Gardens. Environ. Entomol. 2017, 46, 1313-1321.

47. Otterstatter, M.C.; Whidden, T.L.; Owen, R.E. Contrasting frequencies of parasitism and host mortality among phorid and conopid parasitoids of bumble-bees. Ecol. Entomol. 2002, 27, 229-237. [CrossRef]

48. Kim, J.Y. Influence of resource level on maternal investment in a leaf-cutter bee (Hymenoptera: Megachilidae). Behav. Ecol. 1999, 10, 552-556. [CrossRef]

49. Peterson, J.H.; Roitberg, B.D. Variable flight distance to resources results in changing sex allocation decisions, Megachile rotundata. Behav. Ecol. Sociobiol. 2016, 70, 247-253. [CrossRef]

50. Muller, C.B.; Schmid-Hempel, P. Variation in life-history pattern in relation to worker mortality in the bumble-bee, Bombus lucorum. Funct. Ecol. 1992, 6, 48-56. [CrossRef]

51. Muller, C.B.; Schmid-Hempel, P. Correlates of reproductive success among field colonies of Bombus lucorum: The importance of growth and parasites. Ecol. Entomol. 1992, 17, 343-353. [CrossRef]

52. Owen, R.E.; Rodd, F.H.; Plowright, R.C. Sex ratio in bumble bee colonies: Complications due to orphaning? Behav. Ecol. Sociobiol. 1980, 7, 287-291. [CrossRef]

53. Goulson, D.; Whitehorn, P.; Fowley, M. Influence of urbanisation on the prevalence of protozoan parasites of bumblebees. Ecol. Entomol. 2012, 37, 83-89. [CrossRef]

54. Bloch, G. Regulation of queen-worker conflict in bumble bee (Bombus terrestris) colonies. Proc. R. Soc. Lond. B Biol. Sci. 1999, 266, 2465-2469. [CrossRef]

55. Vogt, D.F. Thermoregulation in bumblebee colonies. II. Behavioral and demographic variation throughout the colony cycle. Physiol. Zool. 1986, 59, 60-68. [CrossRef]

56. Malfi, R.L.; Roulston, T.H. Patterns of parasite infection in bumble bees (Bombus spp.) of Northern Virginia. Ecol. Entomol. 2014, 39, 17-29. [CrossRef]

57. Carvell, C.; Bourke, A.F.; Dreier, S.; Freeman, S.N.; Hulmes, S.; Jordan, W.C.; Redhead, J.W.; Sumner, S.; Wang, J.; Heard, M.S. Bumblebee family lineage survival is enhanced in high-quality landscapes. Nature 2017, 543, 547-549. [CrossRef] [PubMed]

58. Hernandez, J.L.; Frankie, G.W.; Thorp, R.W. Ecology of urban bees: A review of current knowledge and directions for future study. Cities Environ. (CATE) 2009, 2, 3. [CrossRef]

59. Lowenstein, D.M.; Matteson, K.C.; Xiao, I.; Silva, A.M.; Minor, E.S. Humans, bees, and pollination services in the city: The case of Chicago, IL (USA). Biodivers. Conserv. 2014, 23, 2857-2874. [CrossRef]

60. Matteson, K.C.; Grace, J.; Minor, E.S. Direct and indirect effects of land use on floral resources and flower-visiting insects across an urban landscape. Oikos 2013, 122, 682-694. [CrossRef]

(C) 2018 by the authors. Licensee MDPI, Basel, Switzerland. This article is an open access article distributed under the terms and conditions of the Creative Commons Attribution (CC BY) license (http://creativecommons.org/licenses/by/4.0/). 